\title{
VIOLÊNCIA ESCOLAR EM MOÇAMBIQUE: UMA REFLEXÃO SOBRE AS PRÁTICAS DOCENTES
}

Lourenço Eugénio Cossa ${ }^{1}$

\section{Resumo}

Neste artigo, são apresentadas práticas de violência escolar dentro do Sistema Nacional de Educação (SNE) em Moçambique. Tais práticas são contextualizadas e questionadas desde perspectivas sócio-político-culturais e humanas como também a partir do aporte teóricometodológico da Análise de Discurso de linha francesa fundada por Michel Pêcheux, visando refletir em torno dos efeitos de sentidos que permeiam o discurso do sujeito professor mediante a sua prática. Mesmo que questionado, o funcionamento do discurso pedagógico se assenta ainda no discurso de tipo autoritário, o que justifica um estudo cujo enfoque é a violência escolar e social produzida contra o aluno. Para tanto, são analisados recortes discursivos que evidenciam ações ainda presentes na escola e apontadas como promotoras de perda de autoestima, evasão e insucesso escolar. Os efeitos de sentidos identificados evidenciam práticas coercivas veladas, algo contraditório aos discursos oficialmente apresentados pelo SNE.

Palavras-chave: Práticas Docentes; Violência Escolar; Análise do Discurso; Efeitos de Sentidos

\section{INTRODUÇÃO}

Refletir a respeito das práticas docentes é colocar em cena discursos e práticas

\footnotetext{
${ }^{1}$ Mestrado e Doutorado em Educação pela Universidade Federal do Rio Grande do Sul, membro do GEARTE e do GPEAD, Professor no Departamento de Design e Multimídia na Universidade Pedagógica em Maputo (Moçambique). Endereço: Rua Paulo Gama, 110 - Farroupilha, Porto Alegre - RS, Brasil, 91501-970 (51) 33083601. Endereço eletrônico: faysakho@yahoo.com
} 
advindos do trabalho quotidiano dos professores nas instituições escolares do Sistema Nacional de Educação (SNE) em Moçambique. Estes discursos e práticas, por estarem articulados às expectativas dos diferentes atores sociais, são permeados por conflitos, disputas e interesses diversificados. Ora como terreno das realizações profissionais e gratificações, ora como espaço de lutas e reivindicações. O professor considera, por vezes, a escola como seu reduto, compreendendo-se como dono de seus alunos - o que potencializa de diversas formas para aperfeiçoar o desempenho dos mesmos e, em outros casos, manipular seus instrumentos de produção. Por vezes, transforma sua prática didática em centro de lutas, de reivindicações silenciosas.

Ao falarmos a respeito das práticas docentes, colocamos em cena contextos sociais que se aproximam do conceito de formação discursiva (FD), pois, no permeio desta, operam sentidos historicamente construídos os quais não estão isentos do meio social circundante. $\mathrm{O}$ conceito de formação discursiva, “[...] permitindo o enfoque do sentido mesmo, é profícuo como referência para visualizar-se uma certa rede de sentidos outros” (MUTTI, 2005, p. 282). A relação entre práticas docentes e formações discursivas se coloca na medida em que os discursos que circulam no permeio destas práticas, e que naturalizam determinadas formas de ser e estar na escola, se regem a partir da apropriação e cristalização de determinados sentidos. A este respeito, Pêcheux e Fuchs (1975, p. 167) referenciam que “[...] toda formação discursiva deriva de condições de produção específicas" (grifos dos autores), destacando que as formações ideológicas

[...] "comportam necessariamente, como um de seus componentes, uma ou várias formações discursivas interligadas que determinam o que pode e deve ser dito (articulado sob a forma de uma harenga, um sermão, um panfleto, uma exposição, um programa etc.) a partir de uma posição dada em uma conjuntura", isto é, numa certa relação de lugares no interior de um aparelho ideológico, e inscrita numa relação de classes. (PÊCHEUX; FUCHS, 1975, p. 166-7, grifos dos autores).

Desse modo, o conceito de formação discursiva se coloca em relação com as formações ideológicas, já que “[...] as formações discursivas (FD) são componentes das formações ideológicas (FI), pois a ideologia tem a sua manifestação concreta no discurso, ou seja, as FD materializam o ideológico presente nas formações sociais, nas relações do homem com o mundo" (DRESCH, 2005, p. 95) ou, como acentuam Pêcheux e Fuchs (1975, p. 167), “[...] as formações discursivas intervêm nas formações ideológicas enquanto componentes".

Cabe ressalvar, ainda, o lugar para o qual lançamos nosso olhar, a escola: ela atrai não 
somente o professor, mas também diferentes atores sociais, políticos. É neste cenário que projetamos focalizar as práticas que se observam na interação entre professores, alunos e pais no Sistema Nacional de Educação (SNE) em Moçambique. Assim, no desenvolvimento do artigo, tais práticas são contextualizadas e questionadas, considerando expectativas sóciopolítico-culturais e humanas amplas e pressupostos teóricos evidenciados nos relatórios da Organização Mundial da Saúde (OMS) e pelos autores Maurice Tardif e Claude Lessard entre outros. Além disso, a reflexão será consubstanciada no referencial teórico-metodológico da Análise do Discurso (AD) francesa fundada por Michel Pêcheux. Este suporte teóricometodológico visa a possibilitar que se reflita a respeito dos efeitos de sentidos que permeiam o discurso do sujeito professor mediante a sua prática pedagógica.

Assim, dentre as várias práticas que merecem ser abordadas de modo a promover a reflexão sobre as mesmas, destacamos a violência escolar, uma prática coerciva que interage com alguns aspectos culturais e que entra em contradição com interesses sociais mais amplos, chegando, em muitos casos, a afetar o desenvolvimento saudável da prática docente que se almeja nos discursos públicos institucionalizados. Ao mesmo tempo em que esta prática é tida como não desejável pelo discurso pedagógico, observa-se que o funcionamento desse se assenta no discurso autoritário e atribui legitimidade a ela, para além de outorgar o professor como agente exclusivo (ORLANDI, 1996). Segundo Eni Orlandi (op. cit., p. 17), “[...] mais do que informar, explicar, influenciar ou mesmo persuadir, ensinar aparece como inculcar".

\section{CONSIDERAÇÕES SOBRE VIOLÊNCIA}

Antes de aprofundarmos a nossa abordagem, convém situar a que violência estamos a nos referir. Existem vários estudos que definem o que é a violência e como ela se faz nos meios sociais. Para refletirmos em torno dessa temática, recorremos aos relatórios da Organização Mundial de Saúde (OMS) e aos estudos da Fundação para o Desenvolvimento da Comunidade de Moçambique (FDC) dado serem instituições que vêm mostrando preocupações no sentido de tentar compreender os fenômenos da violência de modo a influenciar estados e governos em políticas que previnam e tratem da mesma. Os estudos que orientam para a compreensão e reflexão relativamente à violência são vários e se associam a teorias sociológicas, criminais, médicas entre outras.

A Organização Mundial da Saúde (OMS) define a violência como o uso de força física 
COSSA, Lourenço Eugénio.

ou poder, em ameaça ou na prática, contra si próprio, outra pessoa ou contra um grupo ou comunidade que resulte ou possa resultar em sofrimento, morte, dano psicológico, desenvolvimento prejudicado ou privação (WHO, 1996; DAHLBERG; KRUG, 2007). Ao se acrescentar estados como desenvolvimento prejudicado ou privação, o relatório da OMS alarga o conceito da violência às práticas políticas e culturais existentes no meio social. Sabese da existência de práticas que, embora tidas como próprias aos valores culturais das comunidades nas quais elas ocorrem e, portanto, normais, cristalizadas e reconhecidas com bônus valorais, interferem no desenvolvimento integral dos sujeitos. Para consubstanciar esta posição, o relatório da Global Initiative to End All Corporal Punishment of Children GI das Nações Unidas refere que:

Tal como na maior parte do mundo, em Moçambique os castigos corporais contra os menores não são proibidos, pelo facto de o recurso ao castigo corporal como forma de disciplinar a criança ser cultural e legalmente aceite e praticado. Em casa, na escola e nos centros alternativos de cuidados e educação a menores, a violência vigora como instrumento de punição. (FDC, 2008, p. 15).

Com o intuito de clarificar esta temática que é a violência, o sociólogo Carlos Serra (2014, p. 8) defende que a violência é um “[...] dano físico, psicológico e/ou moral infligido a outrem (individual ou coletivamente considerado) ou em algo, de forma continuada ou não, direta ou indireta, com consequências lesivas que, no limite da interação social, podem conduzir à morte”. De acordo com este autor, “[...] no dia-a-dia, a nossa concepção de violência baseia-se na violência violenta: um tiro, uma agressão, uma ira sem fronteiras, uma manifestação popular, uma carga policial, uma emboscada de guerrilheiros como acontecia em Moçambique" (SERRA, 2014, p. 8-9).

Contudo, existem outras formas de violência que, em muitos casos, não são percebidas como violência e, por conseguinte, não são susceptíveis de mobilização para a sua erradicação. Nos contextos sociais em Moçambique, é condenada a violência que envolve armas convencionais e brancas, mas se corre para assistir, aplaudir e estimular indivíduos em conflito ou em pancadarias. Ademais, pais e encarregados de educação ficam indiferentes à agressão de seus filhos pelos professores por perceber aquela violência como forma de educar.

Um outro modelo de compreensão da violência que pode ser considerado, aqui, é o ecológico. Tendo surgido no fim da década de 1970, este modelo foi inicialmente aplicado aos casos de abuso infantil e, subsequentemente, à violência juvenil. Ele explora a relação entre os fatores individuais e contextuais e considera a violência como produto dos múltiplos níveis de 
influência sobre o comportamento (WHO, 1996; DAHLBERG; KRUG, 2007). Entendendo a violência como um fenômeno multifacetado na interação entre elementos individuais, contextuais e sociais, o modelo teórico ecológico defende que os fatores de risco da violência podem ser avaliados através de quatro níveis: individual, familiar/interpessoal/relações ${ }^{2}$, comunitário/comunidade $^{3}$ e macrossocial ou da sociedade, influenciando-se mutuamente e interagindo como fatores de risco da violência (ZACARIAS, 2014). Consoante tal modelo, vários riscos a nível individual e familiar/interpessoal podem ser causadores da violência como: o fator biológico, o abuso durante a infância, idade, gênero, toxicodependência em decorrência do consumo de álcool e outras drogas, desemprego, baixo nível educacional entre outros (ZACARIAS, 2014).

No entanto, pensamos que a inclusão da baixa escolaridade como fator que pode conduzir o indivíduo à violência tem relação com a circularidade constituída pela vitimização da pobreza, exclusão social e econômica, ou seja, está articulada à "naturalização da violência", o que constitui “[...] novas formas de violências, agudizadas pelo crescimento das marginalizações, das pauperizações" (ANDRADE, 2014, p. 15). Em outras palavras, dizer que a pessoa é violenta em decorrência da baixa escolaridade é tão questionável quando dizer que "[...] as pessoas são violentas porque possuem um coeficiente de violência inato, que os homens batem nas mulheres porque são violentos, que os pobres são pobres porque são preguiçosos, que a oposição política faz o que faz e diz o que diz porque é visceralmente violenta" (SERRA, 2014, p. 8).

Os riscos constatados no segundo nível, o familiar/interpessoal ou de relações se consubstancia nos elementos enquadrados nas relações sociais contíguas, ou seja, as relações sociais mais próximas ${ }^{4}$, tomando como referência a vizinhança, os amigos, colegas e membros da família que partilham os mesmos ideais ou prestam apoio social material, espiritual ou emocional. Zacarias (2014) realça esse nível, referindo que o ambiente ou as circunstâncias em que a violência social ocorre é influenciada por comportamentos aceites e instigados pelos pares com quem a pessoa mantém relações sociais próximas.

Já o terceiro nível, relacionado com os fatores comunitários/comunidade, é apontado como o que influencia as taxas de excluídos socialmente e economicamente, agudizando-se a pobreza, mobilidade e mortalidade na violência social.

\footnotetext{
${ }^{2}$ Cf. DAHLBERG, Linda L.; KRUG, Etienne G. Violência: um problema global de saúde pública. Ciência \& Saúde Coletiva, 11(Sup): 1163-1178, 2007.

${ }^{3}$ Idem.

${ }^{4}$ Idem.
} 
COSSA, Lourenço Eugénio.

Zacarias (2014, p. 83) realça que:

Estes fatores estão inseridos num conjunto de redes de organizações sociais formais ou informais, a título de exemplo, grupo de amigos ou colegas de trabalho, instituições como igrejas, escolas, instituições que aglutinam os indivíduos na sua comunidade e os interligam com as normas culturais e práticas socialmente aceites.

Entretanto, estudos demonstram que as oportunidades para que a violência ocorra são maiores em alguns contextos do que em outros - por exemplo, em áreas de pobreza ou deterioração física, ou onde há escasso apoio institucional (DAHLBERG; KRUG, 2007).

O último nível do modelo ecológico, o macrossocial ou da sociedade, incute ou criminaliza a violência social, associando-a a crenças culturais, dogmas, regulamentos e leis, dos quais se destacam normas gerais e públicas sobre educação, família e poder, gênero, opções políticas, entre outras (ZACARIAS, 2014). Dessa forma, nos sujeitos podem-se produzir ou reproduzir práticas nefastas a outrem, mas que, na percepção de certos grupos, representam o que deve ser feito.

No tempo da colonização portuguesa em Moçambique, na pretensão de escolarização dos nativos, que não se identificavam com o sistema educativo direcionado aos interesses de Portugal, pessoas eram perseguidas de casa em casa e levadas à força para escola sob a opressão do cassetete e/ou da palmatória. Na oralidade, nossos avós contam que se escondiam no mato e em cima das arvores para não serem coagidos forçosamente à ida para a escola ou à realização de trabalho forçado. Estas práticas enviesadas pelas políticas coloniais de educação e trabalho forçado produziram, na nossa ótica, efeitos de sentidos que posicionam a educação formal/escolarizada num local a se temer, pois a reguada e a palmatória faziam parte dos instrumentos estimuladores educativos para os nativos.

Zacarias (2014), fazendo uma breve contextualização, aponta a teoria da aprendizagem social como a que aborda a violência social como um comportamento assimilado que pode ser transmitido de uma geração para sua subsequente. Já que a violência é constitutiva do social e que nenhuma violência é exterior ao social (SERRA, 2014), esta constitui a memória e o fazer social em termos das pretensões educativas individuais, relacionais, comunitárias e macrossociais.

De acordo com Zacarias (2014), o modelo ecológico explicita quão intrincadas são as interações entre os diferentes fatores de risco social para que um indivíduo se torne vítima ou perpetrador dos diferentes tipos de violência social. Professor que estudou coagido por 
reguadas, varas e palmatórias, usualmente, pode, se não estiver em contato com outras formações discursivas que se regem a partir de sentidos alternativos, observar o método de estímulo-resposta/coerção física da escola tradicional como o mais viável para o aprendizado escolar.

É pertinente referir que a naturalização da violência e, em particular, da violência escolar ou contra a criança se mostra perambular entre os vários níveis de risco.

No nível macrossocial/sociedade, nos fatores familiares/interpessoais, comunitários e/ou no nível individual se criam desequilíbrios do poder com uma ordem social onde o professor, o Estado e o homem apresentam-se com direitos reservados. Isso torna, segundo Zacarias (2014), as mulheres e crianças vulneráveis à violência interpessoal como aquela praticada contra parceiros íntimos e o abuso durante a infância. Em contextos urbanos e periurbanos das cidades em Moçambique, ainda sucedem situações em que determinados encarregados de educação autorizam o professor de seu filho a bater no caso de a criança ou o jovem "fazer indisciplina". Importa referir que indisciplina, segundo nossa experiência e consoante a compreensão vigente em Moçambique, pode ocorrer na situação do/da aluno/criança ser surpreendido a falar sua língua nativa na sala/escola. E a violência, também, pode suceder na tentativa de fazer o aluno saber dos conteúdos durante as aulas.

Para além dos estudos já abordados acerca da temática da violência, os estudos realizados pela FDC apontam três categorias: a violência direta e física, a violência indireta ou estrutural e a violência cultural (GALTUNG, 1996; OMS, 2002; FDC, 2008).

$\mathrm{Na}$ violência direta e física, subjaz a perspectiva do agressor visível que, quando rastreado, pode levar à identificação do ator ou dos atores praticantes da mesma. Esta violência pode ser dividida em física e verbal: a primeira tem consequências diretas no corpo, e a segunda, na mente e no espírito. (GALTUNG, 1996; OMS, 2002; FDC, 2008).

Já, a violência estrutural ou indireta provém da estrutura social, seja de caráter familiar, estatal ou de alianças de Estados, entre outras. As duas maiores formas de violência estrutural são a repressão política e a exploração econômica. (GALTUNG, 1996; OMS, 2002; FDC, 2008).

A violência estrutural é de caráter sutil, para alguns autores, e constitui uma das formas mais expressivas de violência por ocorrer com permissão de normas de ordem social. Só pode ser percebida considerando o contexto social e histórico no qual ela é produzida, tendo em conta os interesses e valores concretos, que caracterizam cada sociedade ou cada 
grupo social, num determinado momento histórico. (OMS, 2002; FDC, 2008).

Por último, a violência cultural é considerada como se expressando de forma simbólica em alguns aspectos de uma religião e ideologia, linguagem e arte, ciência e lei, imprensa, educação. Ela pode ser usada para legitimar a violência direta ou a estrutural, de modo a que seja vista como certa ou pelo menos não errada. (GALTUNG, 1996; OMS, 2002; FDC, 2008).

De acordo com estudos da FDC, uma Organização não Governamental moçambicana, “[...] a violência contra menores ocorre em diferentes meios e ambientes sociais, nomeadamente na família, nas escolas, em instituições como orfanatos e outros locais de acolhimento, nas ruas, nos locais de trabalho e nas prisões" (FDC, 2008, p. 9). Por ser ainda uma prática comum na educação das crianças em sociedades moçambicanas, o recurso ao uso da vara e das chineladas é considerado como um método educativo eficaz, portanto, se configura como pré-construído entre os pais e professores. A este respeito, é possível destacar que:

\begin{abstract}
As formas de alienação e agressão psíquica e social, a violência, nunca podem ser reconhecidas como condições definidas e constitutivas da autoridade civil, ou como os efeitos ambivalentes do próprio instinto social. Eles são sempre explicados como presença estrangeira, oclusões do progresso histórico, a forma extrema de percepção equivocada do homem. (BHABHA, 2005, apud COSSA, 2007, p. 38).
\end{abstract}

Assim, se evidencia a violência como uma prática normativa e se desperdiçam oportunidades de diálogo e de uso de meios motivadores saudáveis que provavelmente desenvolveriam as crianças cognitivamente de forma ampla.

Sabe-se que a escola está inserida em um contexto social, mas, ao mesmo tempo, encontra-se sob a orientação das políticas estatais, de desenvolvimento, controle político e regularização social "equilibrada" segundo pressupostos da homogeneidade, do "estado nação". Mas, será que a autonomia da escola em relação à organização institucional é possível? Será que a autonomia do professor em relação à organização da escola é possível?

Alguns discursos apontam a autonomia do professor, outros, a autoridade/não autoridade do professor/escola, em relação aos alunos, ou seja, o controle/não controle sobre estes. Esses dizeres estão contidos nos discursos escolares das abordagens referentes a estruturas escolares estáveis. Entretanto, esse pensar não deve ser apartado do contexto social atual em que a escola está inserida, afinal, pai, mãe, tia, avós do aluno ou outros cuidadores, na maioria do tempo, assumem a educação da criança ou intervêm na escolarização desta e, 
certamente, contribuem na formação do educando.

A forma como o/a aluno/filho/criança é educado/a em casa certamente contribui na formação/não formação desse na escola. Portanto, a qualidade da educação é também o reflexo contextual social. A violência escolar, a renitência/resistência do professor perante ao novo, a não aceitação da crítica e da supervisão são reflexos sociais e isso também se reflete na/o criança/jovem/aluno.

\section{A PARTILHA DE RESPONSABILIDADE ENTRE ESCOLA E FAMÍLIA}

A responsabilidade da escola, exclusivamente, para com o aluno conduz à tendência cristalizada de a instituição concentrar sua tarefa na moralização e ideologização. É certo que a moral e o controle são pressupostos que caminham paralelamente com o projeto educativo institucional. Segundo Orlandi (1996, p. 22), “[...] a escola é a sede da reprodução cultural e o sistema de ensino é a solução mais dissimulada para o problema da transmissão de poder, pois contribui para a reprodução da estrutura das relações de classe dissimulando, sob a aparência da neutralidade, o cumprimento dessa função". Contudo, a partilha da responsabilidade pelo educando entre a escola e a família torna-se pertinente.

A realidade discursiva aponta que a escola é ou se tornou a instituição que equilibra o social e, também, é responsável pelo futuro da sociedade, daí ser necessária a formação de qualidade do professor e, consequentemente, do aluno. Isso demanda a permanência do aluno por mais tempo na escola, nos estudos, demanda mais conhecimentos, desporto, e outras tarefas que possibilitem a formação integral do sujeito social. Entretanto, esses pressupostos e desejos, por vezes, encontram confrontos de várias ordens. A indiferença para com as diferenças e particularidades culturais do aluno, o desencontro da realidade institucional escolar com os alunos, a não coincidência entre o aparato formal escolar e o seu contexto em volta, a comunidade escolar etnocultural e linguística, constituem, ainda, a realidade contemporânea. É no permeio desta não coincidência que a violência escolar se instala e se naturaliza.

Vários discursos acadêmicos apontam que a valorização dos conhecimentos e saberes “outros" (não legitimados) contribuem na inclusão do outro e abrem o campo do saber, outras esferas do saber, outros campos de conhecimentos, possibilitando a formação integral do ser humano. A confrontação do saber escolarizado com o que está próximo do sujeito projeta um 
espaço de significação (compreensão) para o aluno e, consequentemente, a produção dos sentidos também significativos por ele. Uma tal situação melhora a condição de vida deste, além de, provavelmente, reduzir as evasões escolares ainda habituais em sociedades moçambicanas.

Aprofundando o nosso debate, convém lembrar que este trabalho visa evidenciar práticas docentes que se instalaram, ao longo da formação da sociedade moçambicana, em particular nos últimos cinquenta anos, e, desse modo, chamar a atenção para os prováveis rumos que se desenham e cristalizam no sistema educacional moçambicano. Esta encenação objetiva clamar por uma reflexão cada vez mais profunda, integrada e sistêmica no meio social.

A emergência desta temática surge a partir de um problema constatado durante a pesquisa de campo que visava à produção de dados para a dissertação de mestrado. Assim, este trabalho tem o seu desenvolvimento paralelo à pesquisa inicial de mestrado que se centrou nas Línguas Nacionais no Sistema Nacional do Ensino para o Desenvolvimento de Moçambique. O artigo é endossado por forma a permitir a reflexão em torno da problemática da violência escolar e social contra a/o criança/aluno. Dado ao contexto da sua escrita, o trabalho aponta o dilema do pesquisador em relação à ética na pesquisa, uma vez que a situação que o originou coloca, em muitas das vezes, este em situação constrangedora que envolveu a aceitação, ou não, pelos sujeitos da pesquisa para a continuidade de seu trabalho.

Assim, para aprofundar o meu entendimento acerca desta abordagem e produzir a minha significação em torno da realidade escolar moçambicana, apropriei-me de pressupostos teóricos pertinentes ao entendimento da prática docente evidenciados por Maurice Tardif e Claude Lessard, no livro $O$ trabalho docente: elementos para uma teoria da docência como profissão de interações humanas, bem como de discussões propostas na disciplina teóricometodológica da Análise do Discurso de linha francesa fundada por Michel Pechêux de modo a poder compreender o assunto em abordagem, analisar os recortes discursivos obtidos nas entrevistas com professores e, finalmente, evidenciar efeitos de sentidos que permeiam a prática docente no ensino moçambicano. Segundo Mutti (2005, p. 282), a

[...] Análise de Discurso pauta-se pelo princípio de vincular sempre os dispositivos teóricos aos procedimentos de análise, por outro lado, esta disciplina se mostra comprometida com a análise, uma análise, portanto, que mostre falhas na língua e equívocos do sujeito; que enfrente a complexidade de mostrar o encontro entre o espaço de interlocução, um espaço de memória e uma rede de questões. 
Contudo, é lícito realçarmos que, apesar da pretensão da disciplina da Análise de Discurso de interrogar sentidos estabelecidos, no processo da análise, o analista não se isenta de afetos (e desafetos) e mobiliza formas de poder diversas (MUTTI, 2005).

$\mathrm{Na}$ abordagem acerca das práticas interativas na ação docente, a presença do discurso é fundamental. Este discurso expõe sentidos que nos auxiliam a compreender o processo da significação dos conhecimentos no ensino e, hipoteticamente, podem ajudar-nos a apreender os sentidos que norteiam a prática educativa. Os sentidos que marcam o trabalho docente evidenciam os contornos do processo sócio-político-cultural do ensino, dando-nos a conjuntura interativa que permeia esta atividade professoral. Assim, enfocar os efeitos de sentidos presentes no trabalho docente é recompor o processo pelo qual os planos e as estruturas se instalam e perduram através do tempo escolar.

É oportuno referir que as práticas escolares refletem posicionamentos discursivos e ideológicos, posições essas que são constituídas em outros discursos (interdiscurso), formações discursivas, ideologias, assentes nos processos históricos sociais e culturais. Courtine (2006, p. 69) explicita que

[...] todo discurso concreto é dominado por um conjunto complexo de discurso, chamado interdiscurso, que serve como 'material discursivo original', ou seja, todo discurso concreto produzido por um sujeito no interior de uma formação discursiva está, portanto, dependente do interdiscurso que lhe é fornecido pelos elementos préconstruídos.

O autor conclui referindo que "[...] é essa exterioridade do que é enunciado que permite pensar a subjetivação do sujeito falante em relação ao sujeito ideológico de seu discurso" (COURTINE, 2006, p. 69).

Recorde-se que Moçambique é um país independente há apenas quarenta (40) anos e a sua estrutura educacional, como em outros países africanos, está assente, ainda, nos modelos ocidentais influenciados pela colonização recente que se regia por uma escola tradicional onde a prática educativa de estímulo-resposta fazia parte das metodologias psicopedagógicos. Nesse sentido, pode-se especular que a memória coletiva, o interdiscurso, ainda é perpassada por algumas práticas educacionais coloniais, já que, apesar das políticas oficiais tenderem a "lutar" pela sua erradicação como também da violência que elas legaram ao Sistema Nacional de Educação, tais práticas ainda influenciam a educação pós-colonial.

Desse modo, a nossa reflexão terá como base a leitura e interpretação de pontos de vista presentes nos recortes discursivos, significando-os desde o nosso contexto sócio- 
cultural-econômico que permeia nossas experiências como aluno e docente, mas sem desconsiderar os ecos das práticas educativas coloniais que talvez ressoem nos pontos de vista sob análise. É no dizer que o sujeito “[...] dá sentido à sua realidade, ao mesmo tempo em que se assujeita - com falhas e equívocos - posicionando-se frente aos discursos que circulam na vida social" (COSSA, 2007, p. 50).

Ao emitir nossos pontos de vistas, ao significarmos algo, colocamos em circulação os nossos conhecimentos, através da nossa constituição como sujeitos socioculturais e pertencentes a um contexto histórico e político. Fazemos isso através da língua que não é homogênea, transparente, e sim heterogênea, suscetível a falhas e ao equívoco, aliás, “[...] o significado da palavra está voltado para fora, para o exterior, ou seja, o sentido não está na palavra em si, mas no mundo em que ela está inserida" (PÊCHEUX, 1969 apud BORGES, 2005, p. 38).

Importa destacar que, ao falarmos em sujeitos socioculturais e pertencentes a um contexto histórico e político, colocamos em evidência a noção de formação discursiva e ideologia. Destarte, referimo-nos à formação discursiva como “[...] aquilo que numa formação ideológica dada - ou seja, a partir de uma posição dada em uma conjuntura sócio-histórica dada - determina o que pode e deve ser dito" (ORLANDI, 2005, p. 43).

No plano discursivo, o jogo complexo das formações discursivas estabelece-se enquanto efeito ideológico onde elas são levadas a incorporar elementos pré-construídos, produzidos fora delas (BATISTOTE, 2005). Ao proferir algo, o sujeito está convicto da autoria e legitimidade no dito. Escapa-lhe que o dito é resultado de outras falas/dizeres existentes na memória discursiva, no interdiscurso, que o constitui. Eni Orlandi (2005) enfatiza que o interdiscurso é todo o conjunto de formulações feitas e já esquecidas que determinam o que dizemos. Para que as minhas palavras tenham sentido é preciso que elas já façam sentido.

Assim, é pertinente enfatizar a importância da prática docente como campo das interações entre o professor e os alunos, dado que a estrutura interna, que parece regular as interações em sala de aula, é convocada nos discursos oficiais a se encontrar em situação de copresença no ato pedagógico. As situações escolares cotidianas, entendidas como situações sociais que se pretendem comuns entre seres humanos referentes às interações que decorrem na sala de aula, são acionadas a enquadrarem-se numa abordagem designada como ecológica (TARDIF e LESSARD, 2008). Para a compreensão mais ampla da abordagem ecológica 
(TARDIF e LESSARD, 2008), Doyle (1986) nomeia seis categorias de interações: a multiplicidade, a imediatez, a rapidez, a imprevisibilidade, a visibilidade e a historicidade.

A abordagem dessas categorias visa a possibilitar o espelhamento dos discursos do sujeito-professor em relação às práticas contrárias que são significadas como catalisadoras de evasão escolar e baixo autoestima do aluno. As práticas coercivas físicas e psicológicas colocam o aluno em uma situação na qual não se considera capaz em determinada atividade do saber. Essa situação é demostrada pela pouca intervenção e argumentação perante o professor. Segundo Doyle (1986), a multiplicidade refere-se ao fato de que, numa aula, ocorrem diversos eventos ao mesmo tempo ou num período muito curto de tempo. É muita informação que interpela o aluno em sujeito dentro da sua cultura, história. Em muitos casos, em turmas superlotadas, o professor encontra dificuldades de lidar com a multiplicidade de eventos que sucedem. O professor expõe os conteúdos e, assim, não resta tempo para um ensino que considere o aluno. Aliado a isso, o próprio sistema linguístico se encontra distante desses intervenientes da escolarização - os educandos.

Outra categoria é a da imediatez que significa que os eventos que ocorrem durante uma aula chegam, geralmente, sem previsão nem anúncios, necessitando de adaptações e estratégias imediatas, espontâneas. Em um sistema educativo de imposição, em que as falhas do sistema educativo são apontadas a partir da resposta dos alunos, o fracasso do aluno é significado como fruto de seu comportamento de não gostar de leitura, de não falar português corretamente. O aluno é culpabilizado. Perde-se a oportunidade, nestas interações, de promover ações enriquecedoras de seu contexto sociocultural e linguístico. Bruner (1978, p. 18) sugere que

[...] um importante ingrediente que possa conduzir o êxito do aluno no processo da educação é um sentimento de excitação pela descoberta - descoberta de regularidades de relações antes não reconhecidas e de semelhanças entre ideias, de que resulte um sentimento de autoconfiança quanto às próprias capacidades.

Casos como esses surgem, provavelmente, devido ao currículo que pouco desenvolve, no/na aluno/criança, atitudes em relação à aprendizagem, à investigação, em relação ao modo de imaginar a solução, ter intuições e palpites quanto à possibilidade de o aluno resolver, por si só, os problemas (BRUNER, 1978).

Em outras circunstâncias, estes casos ocorrem devido à falta de diálogo, numa relação vertical entre aluno-professor, uma vez que a aproximação do professor ao aluno, ou vice- 
versa, por vezes, é entendida por determinados docentes como possibilidade de o aluno extrapolar em seus direitos, não respeitando mais o docente. O professor, na sua prática, se fecha em si, impossibilitando a abertura do aluno.

Indo a outra categoria, o autor aponta a rapidez caracterizadora do desenvolvimento próprio aos acontecimentos durante a aula, sua sucessão, seu encadeamento, sua fluência. Na realidade moçambicana, com as turmas superlotadas, a rapidez é forçosamente catalisada, na minha ótica, pela preocupação com o cumprimento dos programas letivos que se seguem à risca. Com pouca interação professor-aluno e com as limitações provenientes da circularidade dos sentidos, adicionadas à formação não contextualizada do professor em relação à cultura do aluno, verifica-se pouca manobra, criatividade e poucas intervenções ousadas por parte do professor, o que desemboca na ausência de paciência e afeto deste para os educandos. O livro didático é encarado como instrumento a ser seguido. Cabe ao docente cumprir o que está traçado nos manuais de orientação. Entretanto, isto não nos habilita a afirmar que não existam docentes ousados e com capacidade de aproveitar acontecimentos suscetíveis de serem explorados e, desse modo, enriquecer a aula e tornar o processo interativo rico em aprendizado. "Essa rapidez dos acontecimentos exige uma atenção constante sobre a tarefa em andamento e a realização da ação do grupo e dos indivíduos da classe" (TARDIF; LESSARD, 2008, p. 233).

Outra categoria da ecologia da classe apontado por Doyle (1986) é a imprevisibilidade que significa que os acontecimentos, ao longo de uma aula qualquer, podem surgir de forma imprevista, desviada, inesperada, surpreendente, em suma, podem iniciar-se sem planejamento na medida em que a trama das ações é desenvolvida. Pode-se, sim, prever e planejar bem a aula, mas as ações dos atores, dos alunos e do professor provocam rupturas, deslocamentos, desvios e recuos de graus variados em relação ao planejamento.

A visibilidade exprime o facto de uma aula ser uma atividade pública desenvolvida na presença de pessoas que são simultaneamente participantes. O professor não pode ocultar nada aos alunos. Tudo o que ele faz é suscetível de interpretação. As interações entre os membros da classe vão tomando, imediatamente, um aspecto coletivo, social.

A última categoria é a historicidade, significando que as interações entre os alunos e os professores acontecem dentro da trama temporal - diária, semanal, anual.

Entretanto, segundo Doyle (1986), as tramas interativas cotidianas entre professores e alunos são complexas, pois, ao mesmo tempo, estão em ação rotinas e fases de iniciativas, 
interpretações, de intervenções pontuais, bem como a maioria dos componentes do ser humano: a moralidade, a afetividade, a cognição, a vontade e a capacidade de agir sobre o outro, de seduzi-lo, de dominá-lo, de obter seu respeito. Portanto, essas categorias colocam as práticas pedagógicas interativas que se cristalizam e normalizam-se na instituição escolar. Contudo, elas circulam entre interesses próximos, mas, ao mesmo tempo, antagônicos, conforme a mobilidade social que não é estática.

Por um lado, a forma como o Sistema Nacional de Educação se mostra na sua visibilidade, hoje, é fruto da historicização de suas práticas antes coloniais, em que a educação estava atenta apenas aos interesses coloniais, passando, depois, para contextos pós-coloniais com suas tentativas contraditórias de se voltar para o povo moçambicano, mas persistindo práticas homogeneizadoras que sufocam o sujeito interveniente do mesmo sistema. Por outro lado, esse sistema projeta suas ações e discursos de integração do percurso que flui dentro dos pressupostos normatizadores do processo educacional, delineados, mas, com os acidentes sócio-históricos culturais, eles acabam tomando rumos não previstos, trazendo ao lume o fracasso escolar.

\section{CONTEXTO E PRÁTICAS NA DOCÊNCIA}

A identidade do professor em Moçambique carrega prestígio devido à possibilidade de sua prática docente ser transformadora do sujeito menosprezado pela sua qualidade nativa, sem escolarização e suscetível a "emprego subalterno" como estivador, des/carregador de sacos em detrimento do sujeito escolarizado com "emprego de escritório", portanto, "importante" no contexto social colonial ou pós-colonial. Pela sua prática, o professor tinha, primeiramente, uma vida facilitada através de auxílio social manifestado pelos beneficiários do seu ofício, ou seja, era comum, nos tempos não distantes, que alunos procurassem o docente, inclusive até nos seus aposentos, com intuito de o auxiliar nos seus afazeres domésticos, até no cultivo de sua machamba ${ }^{5}$, isso nas zonas rurais e periurbanas. Entretanto, nos dias que correm, esta prática é pouco visível nos meios urbanos e até no campo.

O que se coloca é que, no permeio desta prática quase que recíproca entre professoraluno, nos tempos referenciados acima, o trabalho docente era usualmente centrado em métodos educativos de persuasão que envolviam estímulo-resposta e eram caracterizados pelo

5 Sítio ou lugar em que se cultiva para produção de bens alimentícios. 
sistema de coerção física e psicológica dos alunos - xipakani (reguada). A tensão catalisada pela dor nas palmas das mãos dos alunos em nome do aprendizado, conhecimentos transformadores do ethos dos sujeitos, estava cristalizada no seio da camada docente de tal modo que se reflete até os dias atuais.

Para consubstanciar este dizer, importa expor narrativas que instigaram esta pesquisa. Como referi antes, este trabalho surge a partir de uma situação paralela à pesquisa que era desenvolvida no mestrado. Enquanto circulava pelos corredores da escola que acolheu o trabalho de investigação, durante intervalos na entrevista com docentes, fui interpelado por ruídos estranhos que saíam de uma das salas. Eram ruídos de palmatória e sussurros de dores de alunos. Constatei que uma professora utilizava métodos coercivos, ou seja, a professora agredia fisicamente os alunos, batendo com uma régua de madeira ou com uma vara. Por sua vez, os alunos tentavam suportar a dor com sussurros - Ish! - em detrimento da reação normal que é repudiar através de choros, grito ou fuga do local/espaço do agressor.

Essa situação criou uma dificuldade, pois estava no local a realizar entrevistas para uma pesquisa dada e que nada tinha a ver com a violência escolar. Como estranho no local, estava entre o dilema de acautelar a professora, denunciar o visto/constatado na direção da escola ou nas autoridades policiais. Contudo, qualquer uma destas medidas, provavelmente, acarretaria num mal-estar no relacionamento que se desenvolvia em decorrência da pesquisa que me levara àquele lugar. Além disso, não sabia se aquele ato constituía uma prática comum naquela escola.

É nesse contexto que decidi enveredar pelo pequeno desvio da pesquisa inicial e passei a incluir, nas questões iniciais da pesquisa, novas indagações referentes à situação que se mostrava - a violência escolar protagonizada pelo professor na sua prática pedagógica. As questões eram: por que razão a professora procedia daquela maneira? Será que, para se alcançar os objetivos didáticos, a melhor metodologia era aquela? Por que os alunos não fugiam daquela situação ou reagiam violentamente perante a dor que a professora lhes causava? Como estes mesmos alunos reagiriam à situação semelhante fora do contexto institucional escolar, na rua, em casa perante à sua agressão? As respostas para o entendimento dessas questões são diversificadas, a começar pelo valor que os sujeitos conferem à escola, coisa aliada com questões socioculturais, políticas, econômicas e ideológicas, advindas da cristalização de certos discursos que desembocam no estar aí das coisas, por vezes acomodando os sujeitos. Os estudos da FDC (2008) consubstanciam a 
emergência da violência contra a criança como um fenômeno que pode advir em consequência de crenças culturais, normas e práticas tradicionais, de fatores socioeconômicos e, até, fruto de causas políticas, em situações de conflito.

Outro fator que gostaria de focar aqui é a cultura do respeito ao mais velho na sociedade moçambicana. Embora esse respeito esteja em crise nas grandes cidades, ainda resiste em determinados contextos sociais: o professor é tido, por vezes, como substituto dos pais da criança em termos educacionais e este nunca pode ser enfrentado verbalmente ou fisicamente, mesmo que suas práticas estejam deslocadas do nosso sentimento humano. $\mathrm{O}$ adulto, os pais assumem posições divinas em certos contextos sociais e, nisso, o cristianismo vem acrescentar quando estabelece que o sujeito deve respeitar os seus progenitores para que seus dias sejam acrescentados.

Outro fator é o medo da repressão do professor em termos de manipulação do seu desempenho acadêmico - reprovação forçada, expulsão e, em certos casos, a provável falta de apoio dos pais perante um contencioso com a escola da criança. São muitos os casos de indiferença dos pais e encarregados de educação da criança perante os problemas de seus filhos na escola e isso, por vezes, é aliado/secundado, hipoteticamente, pela baixa escolaridade ocidental destes e falta do domínio da língua que orienta os discursos públicos, o português. Os pais se veem impossibilitados de dialogar em pé de igualdade com o professor de seus filhos, uma vez que seus conhecimentos são renegados pelo discurso oficial.

Há que se saber, também, que o professor é um sujeito que vive sob a pressão advinda das instâncias superiores que o tutelam, com todos os problemas presentes no Sistema Nacional de Educação de Moçambique: turmas superlotadas ${ }^{6}$, falta de meios materiais adequados para o andamento normal do ensino, como carteiras para os alunos e para ele mesmo, e baixos salários. Mas, como executor dos programas curriculares, ele deve cumprilos plenamente. Em função disso, chega a usar de sua prerrogativa docente e de autoridade na sala de aula e, sob pressão aliada com formação lacunosa e limitada, por vezes, recorre a métodos constrangedores na tentativa de "pôr qualquer coisa" na cabeça das crianças/alunos ${ }^{7}$, método característico da escola tradicional.

A escola tradicional, no campo da sua psicologia de ensino-aprendizagem, foi caracterizada pelo estímulo-resposta. Por exemplo, se o professor dissesse para o aluno " $A$

6 Uma turma da escola primária nas zonas urbanas chega a suportar 70 ou mais alunos.

$7 \mathrm{Na}$ escola tradicional, o aluno é considerado como tábula rasa. Esta escola que caracterizou séculos passados e que até atualmente persiste considerava o professor como centro do saber e o aluno despido deste. 
Lila pula" ou qualquer outra assertiva, o aluno tinha que repetir "A Lila pula", memorizando. Se este não respondesse com rapidez, caía-lhe, sobre a palma da mão, a palmatória. Esse método norteou as práticas docentes dos sistemas colonialistas em Moçambique, produzindo, inclusive, discursos que se cristalizaram em outras práticas sociais e se transformando em préconstruídos - verdades inquestionáveis nas práticas pedagógicas institucionalizadas ou não institucionalizadas, o que se reflete até os dias atuais. A esse respeito, Brandão (2004) referencia o pré-construído como elemento produzido em outro(s) discurso(s), anterior ao discurso em circulação. Assim sendo, todo discurso mantém uma relação essencial com elementos pré-construídos.

\section{ANÁLISE DOS RECORTES DISCURSIVOS REFERENTES ÀS PRÁTICAS DOCENTES}

Perante a situação das práticas docentes caracterizada pela coerção física descrita anteriormente, abordei professores da referida escola para uma entrevista acerca da violência escolar. Seguem alguns recortes discursivos extraídos dessas entrevistas e analisados segundo a vertente teórico-metodológica da Análise do Discurso de linha francesa fundada por Michel Pêcheux. Nos recortes discursivos, o discurso se materializa a partir do contato entre o ideológico e o linguístico, representando, no interior da língua, os efeitos das contradições ideológicas (COURTINE, 2006; BRANDÃO, 2004).

Como uma disciplina teórico-metodológica, a Análise do Discurso centra sua análise na realização de leituras críticas e reflexivas que não reduzam o discurso à consideração de aspectos puramente linguísticos nem o dissolvam num trabalho histórico sobre a ideologia (BRANDÃO, 2004). Desse modo, com os recortes discursivos selecionados e interpretados nesse artigo, visa-se a elucidar o contexto das práticas docentes em abordagem nesse trabalho, promovendo reflexão a respeito das interações dos intervenientes escolares - professores, alunos, pais. Em cada recorte discursivo, colocaremos os nomes fictícios dos professores como forma de ocultar suas identidades. Não é nossa intenção causar qualquer constrangimento ético-profissional, mas sim promover o debate salutar para o desenvolvimento educacional em Moçambique.

A análise é coerente com princípios próprios à pesquisa qualitativa e decorre de intervenções realizadas junto a uma escola do ensino primário da cidade de Maputo, capital de Moçambique. Tem o propósito de identificar e problematizar práticas contrárias ao discurso 
oficial, mas que continuam presentes na sala de aula apesar dos alertas sobre as implicações desses atos vindos de vários organismos nacionais e internacionais. Foram entrevistados, nessa pesquisa, cinco docentes, no entanto, apresentaremos, aqui, as falas de três professores. Dessas entrevistas resultaram os recortes discursivos que constituem o nosso objeto de análise. Convém lembrar, a esse respeito, que "toda prática discursiva está inscrita no complexo contraditório-desigual-sobredeterminado das formações discursivas que caracteriza a instância ideológica em condições históricas dadas" (PÊCHEUX, 1988, p. 213). Daí que, no dizer do sujeito professor, podem ser evidenciados sentidos constituídos e cristalizados que refletem o estar social.

\subsection{Efeito de sentido de estímulo do aluno através de métodos agressivos}

Perguntada acerca da relação professor-aluno e dos métodos coercivos na prática docente, a professora Intase responde:

(1) Intase: O professor tem boa relação com aluno, apesar de ter alguns problemas (risos)... A parte de alguns encarregados, porque os professores, as vezes, aplicam alguns métodos né? ... às vezes tento assustar um bocadinho pra ver se busca a concentração, comportar-se de uma boa maneira... Às vezes ficam aí meio triste né, com o professor, mas o professor busca motivação... As crianças chegam a entender que afinal de contas o professor fez aquilo para me fazer entender isto mais aquilo.

Nessa formulação, a professora deixa transparecer que tem boa relação com aluno, apesar de ter alguns problemas (risos). O riso introduz a insegurança no seu dizer e busca a cumplicidade do interlocutor (nesse caso, o pesquisador), afinal o seu interlocutor faz parte de seu contexto sociocultural. A professora assume como função garantir o aprendizado, contudo, tem problemas: A parte de alguns encarregados, ou seja, os encarregados atrapalham quando os professores, às vezes, aplicam alguns métodos né? Pode-se perspectivar que, do ponto de vista da docente, o uso de práticas coercivas é só um método e mais nada, não se justificando os problemas trazidos pelos encarregados de educação.

O discurso pedagógico em Moçambique ainda está próximo de um método tradicional pensado a partir do behaviorismo segundo o qual o estímulo e a resposta são compreendidos como a forma eficaz de fixar os conhecimentos historicamente acumulados pela humanidade. Esse método era utilizado pelo colonialismo português na história recente de Moçambique. 
COSSA, Lourenço Eugénio.

Método que, aliás, fez com que muitos de nossos avós resistissem e detestassem a escola. Apesar da independência nacional, alguns professores, que são/foram constituídos pelo "discurso autoritário" (ORLANDI, 1996) colonial, carente de argumentos e interatividade com os educandos, na tentativa dever se busca a concentração, comportar-se de uma boa maneira, assustam um bocadinho, batendo nos alunos - não muito, só pra pôr as crianças no lugar, agredindo-os fisicamente e psicologicamente. São vários os apelos sociais das organizações não governamentais no sentido de essa prática ser erradicada da escola e do meio social, mas a construção da maioria desses sujeitos sociais é permeada pelos discursos que apontam a não liberdade de diálogo com o mais novo.

A imposição, em detrimento da negociação sem coerção física ou psicológica, está presente e é vivida em termos práticos na sociedade. Segundo Orlandi (1996, p. 86), “[...] como o discurso pedagógico é um discurso autoritário, não são relevantes, para as suas condições de significação, a utilidade, a informatividade e o interesse do destinatário, dado que a função é a de inculcação".

No entanto, por parte dos alunos, não existem problemas, pois as crianças chegam a entender que afinal de contas o professor fez aquilo para me fazer entender isto mais aquilo. Segundo essa autora, o conhecimento pode se fazer de maneira conflituosa, com rupturas. O conhecimento escolar é o que tranquiliza, ou seja, nós nos conhecemos no saber que é considerado desejável pelos nossos pares e isso é garantido pela reprodução social. Embora, às vezes ficam aí meio triste né, com o professor, mas o professor busca motivação e, assim, segundo a depoente, caminha a tarefa sagrada do professor de mudar e tornear as mentes repletas de ignorância e obscurantismo, ou seja, o professor fez aquilo que era necessário para que o estudante entendesse isto mais aquilo, em outras palavras, os conhecimentos cuja transmissão cabe ao docente.

\subsection{Efeito de sentido de disciplinamento por estímulo e resposta}

Indagando outra professora acerca do método coercivo na ação docente na escola moçambicana, ela responde:

(2) Ntekwase: [...]. Batia se as crianças.... Minha mãe, uma vez disse assim, que existem 
professores que às vezes batiam; tinha problema com encarregados... Por quê? - Porque você tem que bater e saber defender e a criança entender porque que foi castigado... Mesmo um filho que nós temos em casa, você tem que castigar, mas, a saber, porque está a castigar...

Ao situar a ação coerciva no passado - batia se as crianças, a professora tenta escamotear ações que ainda ocorrem até o momento, inclusive no seu local de trabalho. Quando afirma que existem professores que às vezes batiam, implicitamente refere que esses professores ainda existem e projeta a justificação desse ato: tem que bater e saber defender e a criança entender. Ela denota a sofisticação do ato punitivo que ainda prolifera até os nossos dias, esclarecendo que a sua aceitação ou o seu repúdio depende de como o professor bate, ou seja, da criança entender porque que foi castigado. A professora parece buscar alternativa para controlar os sentidos que escaparam do seu controle, o não dito, que escapuliu devido à impossibilidade de controle da língua. Consoante Orlandi (2005, p. 37), “[...] se o real da língua não fosse sujeito a falhas e o real da história não fosse passível de rupturas não haveria transformação, não haveria movimento possível, nem dos sujeitos nem dos sentidos. A língua é sujeita ao equívoco. O sujeito ao significar se significa”.

Por um lado, a professora sabe que, oficialmente, não se deve bater nas crianças, mas, por outro, que ela pode: Você tem que bater. O mais importante é saber defender de tal modo que a criança entenda o porquê do castigo. A marca discursiva tem evidencia uma necessidade, um imperativo, um ato incontornável, provavelmente devido à falta de outras possibilidades ou métodos de ensino. Esse dizer mostra a cristalização do discurso tomado em ato, um pré-construído.

\subsection{Efeito de sentido de coerção física: a inviabilidade pedagógica e o disciplinamento}

Instado a colocar seu pensamento acerca do método de coerção física (reguada) no ensino em Moçambique, o professor responde:

(3) Dlhambo: Eu penso que esse método não é assim... é... viável; embora a porrada, certas vezes, ajuda a disciplinar, a colocar as pessoas, o aluno no lugar dele; a temer, nesse caso. Mas, qual é outro problema? O problema é o aluno, neste caso, já está com medo. Não está com respeito... Não está com respeito, está com medo. Qualquer brincadeira que for a fazer e o professor não gostar, poderá vir a dar uma porrada! 
Então! Ele pode estar lá quietinho, quietinho, mas não estar atento. Só está quietinho por medo de levar porrada... mas não está atento. Então! Esse método não é assim, muito... aplausível.

Indagado se tem presenciado situações envolvendo atitudes violentas, e se elas ocorrem na escola, o professor responde:

(4) Dlhambo: Presenciado, Não! Mas sempre, às vezes tenho... ouço alunos a reclamarem - Ah! Porque o professor fulano faz isto; porque o professor fulano... epál Dá porrada. Então! ... Penso que... existe, mas não em grandes proporções... Não em grandes proporções. Eu penso que mesmo nesse momento em que um professor chega, até ao ponto de aproximar ao aluno dar uma porrada... Certas vezes... Se calhar porque... Chamou atenção duas, três vezes, o aluno não quis ouvir! E, como forma de evitar que possa Ihe tirar para fora, porque também não ia resolver o problema, então, achou ideal que... Com uma porrada poderia Ihe colocar no lugar.

A tomada da palavra pelo sujeito professor Dlhambo, quando diz: Eu penso que esse método não é assim... é... viável, projeta efeitos de sentidos que se configuram na tentativa de pôr em circulação os valores pedagogicamente aceitos e defendidos na atualidade, valores que não coadunam com a produção de violência na escola ou fora dela. Ele não concorda com a violência na prática docente, não a considera como uma presença "viável" no trabalho docente, mas, como membro pertencente à "sua" sociedade e estando a sua tomada da palavra permeada pelos discursos e práticas aceitos socialmente, Dlhambo se contradiz.

Em sua formulação, o sujeito professor mostra a não concordância total com a não violência. Ainda que duvide de valores que percebem a violência como um dos métodos adequados de ensino quando declara esse método não é assim... é... viável, ele expõe a "porrada" como uma opção a ser empregue, principalmente porque ajuda a disciplinar, a colocar as pessoas, o aluno no lugar dele; a temer, nesse caso... Estes dizeres mostram a dualidade dos sentidos de não aceitação e aceitação da violência como componente constitutivo do universo pedagógico.

A posição discursiva do sujeito professor evidencia espaços determinados a serem ocupados, um pelo professor e outro pelo aluno. A ocupação destes lugares se efetiva com eficácia a partir do disciplinamento forçado ou coercivo de modo a se instalar o medo dado que, como afirma Dlhambo, [...] a porrada, certas vezes, ajuda a disciplinar, a colocar as pessoas, o aluno no lugar dele; a temer, nesse caso. 
Contudo, esta situação de disciplinamento coercivo é posta em causa pelos valores socioculturais de respeito acima de tudo; não, pelo medo nas interações interpessoais. A conjunção adversativa "Mas", em Ele pode estar lá quietinho, quietinho, mas não estar atento, projeta a contradição da violência dentro da sala de aula, uma vez que atos violentos instalam trauma, pavor, medo. Somam-se a essa formulação outras duas - O problema é o aluno, neste caso, já está com medo e Não está com respeito - nas quais se percebe que o professor acredita que é a partir do respeito ao próximo, nesse caso, do respeito ao professor, que certamente se produzirá admiração por parte do/da aluno/criança, algo que talvez resulte em aprendizado significativo.

O estado de "estar lá quietinho, quietinho", considerado como sinônimo de disciplina, não garante que o professor tenha a atenção do aluno ou seu interesse pela aula ministrada. Reitera isso o comentário do professor segundo o qual "esse método não é assim, muito... aplausível". A partícula de negação "Não é" volta a confirmar a desaprovação da adoção da "porrada"/violência física na sala de aula, mas esta negação sofre a contradição na "completude" da formulação uma vez que o advérbio "muito" muda o sentido de negação da violência antes posto em circulação e abre brecha para sua aceitação. Em determinadas circunstâncias pode ser praticada, por exemplo, quando o professor chamou atenção duas, três vezes, o aluno não quis ouvir! A chamada de atenção "duas, três vezes", adicionada à desobediência expressa em "o aluno não quis ouvir" esgota todas as possibilidades de diálogo, de interação aluno-professor e vice-versa, desembocando na violência escolar.

Quanto à sua cotidianidade na prática docente, o sujeito professor nega ter alguma vez presenciado a prática da violência. Contudo, pensaque... existe, conquanto sua existência não seja acentuada, pois ocorre não em grandes proporções. Consideramos que ao manifestar estes sentidos, o sujeito professor considera a violência como não muito preocupante haja vista ela assumir uma forma paliativa de resolução de um problema, porque, como propõe Dlhambo, ela corresponde a uma forma de evitar que possa the tirar para fora, porque também não ia resolver o problema, então, achou ideal que... Com uma porrada poderia Ihe colocar no lugar.

É oportuno esclarecer que a disciplina é razoavelmente desejável na ordem social moçambicana. Observando o contexto do Sistema Nacional de Educação em Moçambique, onde coabita a superlotação nas salas de aulas, é difícil imaginar como seria o ensino 
moçambicano sem a disciplina. Aqui, enfocamos a disciplina com sentido de apaziguamento de conflitos durante as interações em sala de aula, promovendo um estar social qualitativo. Dessa forma, a disciplina não deve ser visualizada de forma negativa somente, mas também de forma positiva. Entretanto, ao dizermos isso, não pretendemos conferir mérito à ação docente que foi objeto da fala de Dlhambo.

Num contexto em que o professor precisa conduzir, mais ou menos, 75 a 80 alunos por turmas constituídas por crianças, adolescentes e jovens, a inculcação dos limites é uma ação pactuada entre a família e a escola e está presente na orientação dos sentidos socialmente compartilhados pelos moçambicanos. Contudo, existem professores que, em nome disso, hostilizam os educandos através de atos de violência, manifestando-se, assim, o despreparo e a incapacidade para o diálogo e, por conseguinte, para uma ação educativa significativa. Segundo a FDC (2008, p. 13), “em Moçambique, milhares de crianças têm sido vítimas de violência nos seus direitos fundamentais, incluindo as formas mais extremas de violência, como a violência física e sexual, que dificulta o seu desenvolvimento saudável”.

\footnotetext{
Nos ambientes escolares, a violência é cometida por professores e outros funcionários de escolas, podendo incluir castigos corporais, formas cruéis e humilhantes de punição psicológica, violência sexual e baseada no género e intimidação. Este estudo destaca que os castigos corporais, como bater em crianças com as mãos ou varas, são uma prática comum em muitas escolas de vários países. (FDC, 2008, p. 17).
}

\section{ALGUMAS PALAVRAS FINAIS}

Os métodos coercivos oficialmente foram banidos em Moçambique, mas eles persistem na realidade das práticas docentes em instituições escolares. Apesar dos discursos educacionais atuais enunciarem que o castigo físico não constitui a prática docente na Moçambique independente e é condenado, ele continua presente na escola. A análise de quatro sequências discursivas produzida nesse texto e a identificação, nos enunciados, de efeitos de sentido de estímulo do aluno através de métodos agressivos e de disciplinamento por estímulo e resposta revelam isso. A questão que se coloca é: será que tais práticas acontecem sem o conhecimento das direções escolares, distritais de educação, das cidades ou mesmo do Ministério da Educação? Não estarão essas práticas a camuflar a incapacidade de diálogo em vários setores sociais de Moçambique? No que detém o poder e no que não o detém? No político e no cidadão? 
Em todo caso, o professor é reverenciado na sua profissionalidade pelo compromisso assumido de formador "do homem novo". Além de ser atribuído o papel de salvador a ele, ficando a impressão de que, mesmo sofrendo, tem obrigação, querendo ou não, de andar numa linha muito positiva, toda a sociedade o vê como a força motriz para o progresso do país.

Os efeitos de sentidos constatados evidenciam práticas coercivas veladas, atos nos quais reverberam sentidos contraditórios se considerados os discursos praticados pelo Sistema Nacional de Educação e, também, a tarefa delegada ao docente de contribuir com a formação de uma outra sociedade. Em razão disso, é caso para dizermos que a formação do professor precisa destacar práticas voltadas ao aluno e à construção da consciência de que o docente é um orientador para o despertar das potencialidades do aluno, podendo, dessa forma, contribuir e promover mudanças efetivas e, consequentemente, o desenvolvimento social, cultural, econômico e político de Moçambique. Urge debates e reflexões que conduzam à implementação efetiva de um ensino de qualidade, com práticas educativas voltadas para o aluno, numa partilha de conhecimentos, e para a não violência socioescolar.

\section{VIOLENCIA ESCOLAR: UNA REFLEXIÓN SOBRE LOS DOCENTES DE PRÁCTICA}

\section{Resumen}

En este artículo, se presentan las prácticas de violencia escolar dentro del Sistema Nacional de Educación (SNE) en Mozambique. Esas prácticas son contextualizadas y cuestionadas a partir de las perspectivas sociales, políticas, culturales y humanos, así como del apoyo teórico y metodológico del Análisis del Discurso de la línea francesa fundada por Michel Pêcheux, con el objetivo de reflexionar acerca de los efectos de los sentimientos que subyacen en el sujeto del discurso docente a través de su práctica. Incluso si en duda, el funcionamiento del discurso pedagógico sigue basándose en el tipo autoritario, lo que justifica un estudio centrado en la escuela y en la violencia social producida contra el estudiante. Para este fin, se analizan recortes discursivos que evidencian acciones todavía presentes en la escuela e identificados como promotores de la pérdida de la autoestima, la evasión y el fracaso escolar. Los efectos de los sentidos identificados, muestran prácticas coercitivas con velo, algo contradictorio con los discursos presentados oficialmente por el SNE. 
Palabras clave: Las Prácticas de Enseñanza; La Vviolencia Escolar; Análisis del Discurso; Sentidos Efectos

\title{
SCHOOL VIOLENCE: A REFLECTION ON PRACTICE TEACHERS
}

\begin{abstract}
In this article, practices are presented in school violence within the National Education System (SNE) in Mozambique. Such practices are contextualized and questioned from social, political and cultural perspectives and human as well as from the theoretical and methodological support of the French Discourse Analysis founded by Pêcheux order to reflect on the effects of feelings that underlie the subject of discourse teacher through their practice. Even if questioned, the functioning of the pedagogical discourse is still based on the authoritarian type of discourse, which justifies a study whose focus school and social violence produced against the student. Discursive excerpts are analyzed that evidence still present actions in school and identified as promoters of loss of self-esteem, avoidance and school failure. The effects of identified senses show veiled coercive practices, something contradictory to the speeches officially presented by the SNE.
\end{abstract}

Keywords: Teaching Practices; School Violence; Discourse Analysis; Senses Effects

\section{REFERÊNCIAS}

ANDRADE, Jorge Márcio Pereira de. O que é a violência social? Violências no plural se multiplicam em tempos de biopolíticas? In: SERRA, Carlos (org.). O que é a violência social? Lisboa: Escolar Editora, 2014.

BATISTOTE, Maria Luceli F. Discurso jornalístico: a construção da imagem do povo paresi. In: BARRONAS, Roberto Leiser (org.). Identidade Cultural e Linguagem. Cáceres, MT: Unemat Editora; Campinas, SP: Pontes Editores, 2005.

BORGES, Águeda A. da Cruz. Terra: No limiar dos sentidos. In: BARRONAS, Roberto Leiser (org.). Identidade Cultural e Linguagem. Cáceres, MT: Unemat Editora; Campinas, SP: Pontes Editores, 2005.

BRANDÃO, Helena H. N. Introdução à Análise do Discurso. 2. ed. Campinas, SP: Editora da Unicamp, 2004. 
BRUNER, Jerome S. O processo da educação: atualidades pedagógicas. São Paulo: Ed. Nacional, 1978.

COSSA, Lourenço E. Línguas Nacionais no Sistema de Ensino para o Desenvolvimento da Educação em Moçambique. Dissertação de Mestrado, Porto Alegre: UFRGS, 2007.

COURTINE, Jean-Jacques. Metamorfoses do discurso político: as derivas da fala pública. Tradução: Nilton Milanez, Carlos Piovezani Filho. São Carlos: Claraluz, 2006.

DAHLBERG, Linda L; KRUG, Etienne G. Violência: um problema global de saúde pública. Ciência \& Saúde Coletiva, 11(Sup): 1163-1178, 2007.

DOYLE, W. Classrom organization and management. In: WITTROCK, M.C. Handbook of reseach on teaching. Nova York: MacMillan, 1986.

DRESCH, Márcia. Ideologia - um conceito fundante na/da Análise do Discurso considerações a partir do texto. Observações para uma teoria geral das ideologias, de Thomas Herbert. In: INDURSKY, Freda; FERREIRA, Maria Cristina L. (orgs.). Michel Pêcheux e análise do discurso: uma relação de nunca acabar. São Carlos: Editora Claraluz, 2005.

Fundação para o Desenvolvimento da comunidade (FDC). Violência contra menores em Moçambique - Revisão da Literatura, Estudos e Pesquisas Aplicadas (KULA), Ltda. 2008

GALTUNG, Johan. Peace by peaceful means. Sage Publications: Oslo, 1996.

MUTTI, Regina. O primado do outro sobre o mesmo. In: INDURSKY, Freda; FERREIRA, Maria Cristina L. (orgs.). Michel Pêcheux e análise do discurso: uma relação de nunca acabar. São Carlos: Editora Claraluz, 2005.

Organização Mundial da Saúde (OMS). Relatório Mundial sobre Violência e Saúde, Geneva, 2002. $351 \mathrm{p}$.

ORLANDI, Eni P. A linguagem e seu funcionamento: as formas do discurso. 4. Ed. Campinas, SP: Pontes, 1996.

ORLANDI, Eni P. Análise do Discurso: princípios \& procedimentos. 6. ed. Campinas, SP: Pontes, 2005.

PÊCHEUX, M. Semântica e discurso: uma crítica à afirmação do óbvio. Campinas: Pontes, 1988.

PÊCHEUX, M.; FUCHS, C. A propósito da análise automática do discurso: atualização e perspectivas. In: GADET, F.; HAK, T. (orgs.). Por uma análise automática do discurso: uma introdução à obra de Michel Pêcheux. Campinas: Ed. da Unicamp, 1975/1990.

SERRA, Carlos. Introdução: o rio e as margens do social. In: SERRA, Carlos (org.). O que é a violência social? Lisboa: Escolar Editora, 2014. 
COSSA, Lourenço Eugénio.

TARDIF, Maurice; LESSARD, Claude. $O$ trabalho docente: elementos para uma teoria da docência como profissão de interações humanas. 4. ed. Petrópolis, RJ: Vozes, 2008.

WORLD HEALTH ORGANIZATION (WHO). Global consultation on violence and health. Violence: a public health priority. Geneva, 1996.

ZACARIAS, António Eugénio. Violência social: quo vadis? - Uma visão médico-legal. In: SERRA, Carlos (org.). O que é a violência social? Lisboa: Escolar Editora, 2014.

Data de recebimento: $18 / 02 / 2015$

Data de aceite: 02/03/2015 